\title{
Collapsibility of the relaxed pharynx and risk of sleep apnoea
}

\author{
A. Oliven*, E. Aspandiarov", I. Gankin\#, L. Gaitini" and N. Tov*
}

ABSTRACT: The present study measured hypotonic pharyngeal collapsibility in subjects not known to have obstructive sleep apnoea (OSA), and assessed the variables that affect collapsibility and the relationship with OSA.

The critical value of positive end-expiratory pressure ( $P$ crit) was measured under the hypotonic condition of anaesthesia in 227 subjects who underwent elective surgery. The risk of OSA in this population was estimated using the Berlin questionnaire.

The mean Pcrit for all subjects was positive (above atmospheric), ranging from 0.69 (95\% confidence interval $(\mathrm{Cl})-7.39-8.77)$ to $4.0(\mathrm{Cl}-4.82-12.82) \mathrm{cmH}_{2} \mathrm{O}$ for subjects with low and high prevalence of OSA, respectively. Pcrit $\leqslant-5 \mathrm{cmH}_{2} \mathrm{O}$ was only found in $3.1 \%$ of the study subjects. In the general population, Pcrit was similar in males and females and correlated positively with increasing age, while a correlation with neck circumference was found only in males. Pcrit accounted for only $\mathbf{1 2 . 2 5 \%}$ of the variability in OSA risk score.

In conclusion, subjects with high critical value of positive end-expiratory pressure are at an increased risk for developing obstructive sleep apnoea. However, the human pharynx is prone to collapse and occludes in most people in the absence of neuromuscular support. Therefore, in most subjects, the level of neuromuscular activity may ultimately determine the occurrence of sleep apnoea.

KEYWORDS: Anaesthesia, collapsibility, critical pressure, obstructive sleep apnoea, pharynx, propofol

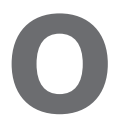
bstructive sleep apnoea (OSA) syndrome is characterised by repetitive collapse and closing of the pharynx during sleep. Many anatomic variations and abnormalities of the upper airway and surrounding structures have been implicated in the pathogenesis of OSA. Regardless of the type of local anatomical or structural factor(s) that increase susceptibility to collapse, the pharynx may be considered to function mechanically as a self-supporting, softwalled collapsible tube [1, 2], conceptually characterised by the Starling resistor model. The collapsibility of such tubes depends on the stability of the walls and the magnitude of the surrounding pressure, and can be defined by the intraluminal pressure under which the tube collapses and occludes, known as the critical value of positive end-expiratory pressure ( $P_{\text {crit }}$ ). Applied to the upper airway, the pharynx of a patient with positive (above atmospheric) Pcrit will be occluded, unless active forces prevent passive collapse. As the collapsibility of the pharynx is determined by both passive mechanical anatomical properties and by active neuromuscular control mechanisms that affect wall stiffness and surrounding pressure, investigators have developed a method to study pharyngeal biomechanics in periods of almost absent neuromuscular activity during sleep [3]. This "passive $P_{\text {crit" }}[4,5]$ was believed to closely represent the anatomic property of the pharynx, determined, to a large degree, by factors such as weight, neck circumference, age, pharyngeal length and other craniopharyngeal properties. It was found to be negative in healthy subjects and positive in patients with OSA [4,5]. Even more convincing was the similar finding observed under anaesthesia and muscle paralysis [6]. Based on these results, several studies have interpreted the findings according to the concept that hypotonic $P$ crit measured during sleep represents anatomic collapsibility $[7,8]$. Accepting this concept would indicate that the healthy pharynx is protected against collapse by its inherent anatomic properties, and that it remains patent even in the absence of neural drive.

This concept seems to contradict the wellestablished observations that the upper airway of most humans is occluded during anaesthesia,
AFFILIATIONS

${ }^{*}$ Depts of Medicine and

${ }^{\#}$ Anesthesiology, Bnai Zion Medical Center, Technion, Haifa, Israel.

CORRESPONDENCE

A. Oliven

Dept of Internal Medicine Bnai Zion Medical Center 47 Golomb Str.

Haifa

Israel

Fax: 97248359770

E-mail: oliven@tx.technion.ac.il

Received:

October 232007

Accepted after revision:

May 232008

STATEMENT OF INTEREST

None declared. 
and that restoration of upper airway patency is the first step in resuscitation of an unconscious patient [9]. The present authors hypothesise that positive $P_{\text {crit }}$ values will be found in most healthy subjects under conditions that lower muscle tone more than sleep. Therefore, the present study assessed flow mechanics and Pcrit in subjects not known to have OSA, under the hypotonic conditions of general anaesthesia. This $P_{\text {crit, }}$ considered to more closely represent passive anatomic conditions, was used to assess the relationships between relaxed pharyngeal collapsibility and OSA risk and anthropometric parameters.

\section{MATERIALS AND METHODS \\ Subjects}

Consecutive patients aged $>18$ yrs, admitted for elective surgery in the Depts of General Surgery, Orthopedics and Urology of Bnai Zion Medical Center (Technion School of Medicine, Haifa, Israel) were recruited to the current study. All patients underwent pre-surgical evaluation by two anaesthesiologists. Inclusion criteria were clearance for general anaesthesia, and understanding and giving informed consent. Patients with cardio-respiratory instability, significant heart or respiratory failure, or debilitating conditions were excluded. The study was approved by the institutional Human Investigations Review Board (Bnai Zion Medical Center, Haifa, Israel).

\section{Anaesthesia}

Induction of anaesthesia in the operating room, before commencing halothane anaesthesia for the planned surgical procedure, was performed in 192 patients with propofol by the same anaesthesiologists involved in recruiting the patients. A loading dose of $2.5 \mathrm{mg} \cdot \mathrm{kg}^{-1}$ followed by bolus doses of $25 \mathrm{mg}$, if required, was administered. To ensure that the findings of the present study were not drug specific, anaesthesia induction was also performed with thiopental $\left(2-7 \mathrm{mg} \cdot \mathrm{kg}^{-1}\right)$ in an additional group of 35 patients. Using continuous positive airway pressure (CPAP) levels that enabled breathing without flow limitation, the present authors aimed to assess the pressure-flow relationships of the patients over a 2-3-min period of stable breathing, 2-3 min after injection of an adequate dose of the anaesthetic drug. Anaesthesia was considered to be adequate for the purpose of the current study when a reaction to pain was completely abolished and adequate ventilation, as monitored by the pneumotachometer (Hans Rudolph, Inc., Shawnee, KS, USA) and pulse oxymetry (Datex Instruments Inc., Baldwin Park, CA, USA), was stable for $\sim 1 \mathrm{~min}$.

\section{Instrumentation and recording procedures}

Subjects were studied in the supine position, with the head on the operating table without a pillow. The subjects breathed through a full-face mask, which was tightly fitted to prevent air leaks. A pneumotachometer was mounted on the mask and connected to a $\pm 2 \mathrm{cmH}_{2} \mathrm{O}$ pressure transducer (Validyne, Northridge, CA, USA) for airflow measurement. The pneumotachometer was connected to a digitised variable pressure source at the inflow port, enabling variation of nasal pressure between 20 to $-10 \mathrm{cmH}_{2} \mathrm{O}$. Nasal pressure was monitored with a catheter connected to a side port of the mask. Flow and nasal pressure were recorded on a Graphtec WR 7700 writer (Graphtec, Tokyo, Japan).

\section{Pressure-flow relationships}

The passive upper airway pressure-flow relationship during anaesthesia was delineated for sleeping patients as previously described [3]. Nasal pressure was maintained at a level sufficient to prevent flow limitation (holding pressure). During stable ventilation, nasal pressure was lowered for four to five breaths randomly to several levels, encompassing four to five levels associated with clear inspiratory flow limitation and a level at which airflow ceased, i.e. completely occluded upper airway. Flow limitation was recognised by the decrease in flow rate associated with the typical flattening of the inspiratory flow curve. After each pressure drop, nasal pressure was raised back to the holding pressure for five to 10 breaths. The studies used were those in which mean flow rate and breathing frequency at the beginning and the end of the pressure-flow evaluation remained nearly unchanged while on holding pressure (variation $<20 \%$ ). Inspiratory flow was measured at the mid-portion of inspiration, at each level of nasal pressure that was associated with flow limitation. The pressure-flow relationship was determined with least square linear regression. This relationship was used to calculate $P_{\text {crit }}$ as the level of nasal pressure below which airflow became zero, as well as upstream resistance (Rus), defined as the slope of nasal pressure-flow.

\section{Assessment of risk for sleep apnoea syndrome}

To estimate the prevalence of sleep apnoea in the subjects, the Berlin questionnaire was used [10]. This rather short and wellvalidated questionnaire estimates the risk of having OSA based on questions about snoring, daytime sleepiness, body mass index (BMI) and hypertension, assigning a score of 0-3. Subjects with an OSA risk score (OSA-RS) of $\geqslant 2$ were considered to be at increased OSA risk. Two experienced anaesthesiologists, who performed the pre-surgical evaluation, also completed the questionnaire. In addition, neck circumference was measured in all patients.

\section{Statistical analysis}

Data are presented as mean \pm SD. Pcrit data are presented as mean (95\% confidence interval (CI)). ANOVA was used for the comparison of results of: propofol and thiopenthal, males and females, and snoring and nonsnoring subjects. Correlations were assessed using the Pearson's correlation method. A linear regression model was used to establish the determinants of $P_{\text {crit }}$ (dependent variable). The independent variables were age, BMI and neck circumference. A p-value of $<0.05$ was considered to be statistically significant.

\section{RESULTS}

In total, 227 subjects were studied. An additional eight subjects who needed a holding pressure of $>15 \mathrm{cmH}_{2} \mathrm{O}$ were excluded due to difficulties with mask fitting, which hindered prevention of air leaks. Typical flow tracings at different CPAP levels, used to construct the pressure-flow relationships and derive $P$ crit and $R$ us, are shown in figure 1 . The mean $P$ crit for all subjects was 1.78 (95\% CI -7.06-10.92) $\mathrm{cmH}_{2} \mathrm{O}$. $P_{\text {crit }}<0$ (passive occlusion below atmospheric pressure) was found in $68(30.0 \%)$ subjects, and only seven (3.1\%) subjects had a $P_{\text {crit }}$ of $\leqslant-5 \mathrm{cmH}_{2} \mathrm{O}$.

\section{Anaesthetics}

A comparison of the anthropometric parameters and findings of the subjects according to the anaesthetics used is presented 

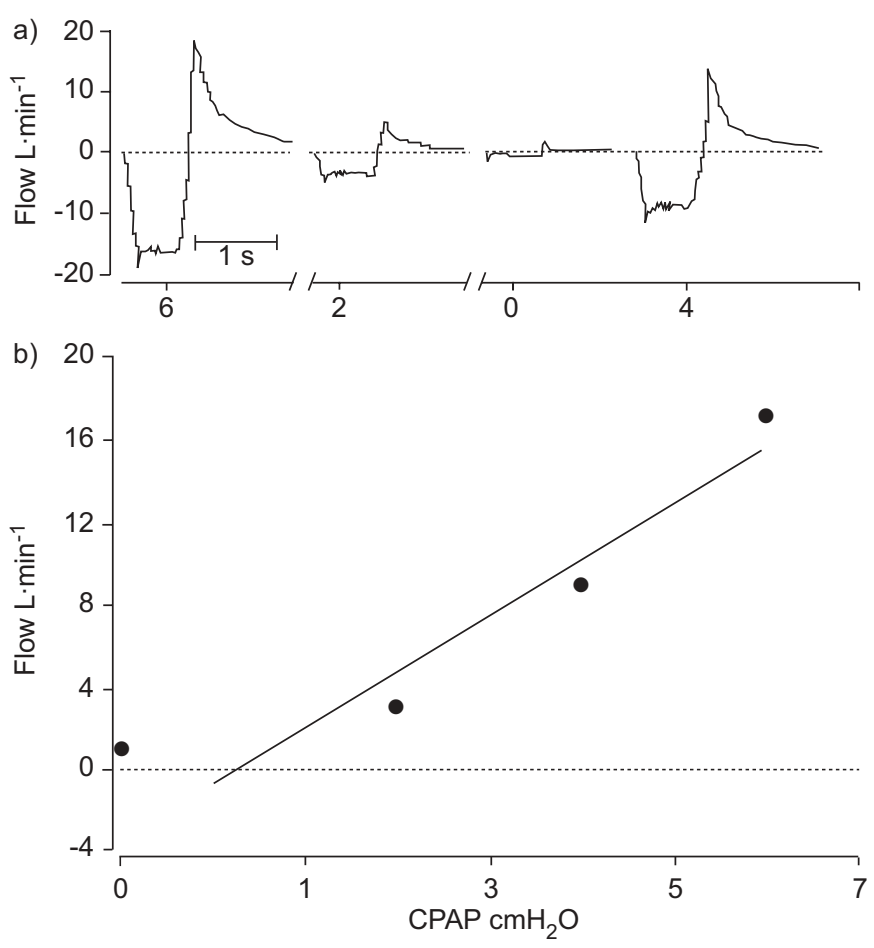

FIGURE 1. Flow tracings of one subject at a) different continuous positive airway pressure (CPAP) levels in random pressure order used to construct the b) pressure-flow relationships. Only flow tracings with flow limitation (typical flat inspiratory flow pattern) were used. The pressure-flow relationship is linear, with high correlation (corr). The critical value of positive end-expiratory pressure ( $P$ crit) is the $x$-intercept (pressure at which occlusion $=0$ flow). The reciprocal of the slope is defined as upstream resistance (Rus). b) $P$ crit: $0.35 \mathrm{cmH}_{2} \mathrm{O}$; Rus: $2.2 \mathrm{cmH}_{2} \mathrm{O}^{-1} \cdot \mathrm{L} \cdot \mathrm{s}^{-1}$; corr: 0.97 .

in table 1. Although not randomised, the two groups of patients were similar in all parameters. Thiopental-anaesthetised subjects tended to have a slightly higher $P_{\text {crit }}$ and OSA-RS, but this difference was not significant ( $\mathrm{p}=0.15$ and 0.23 , respectively). Therefore, further results are presented for all subjects.

\section{Snoring}

Table 2 presents a comparison between subjects that reported persistent loud snoring (as defined in the Berlin questionnaire) and all other subjects. The percentage of males and females was similar in the two groups, but snorers were older and more obese than nonsnorers. Accordingly, snorers had a significantly higher $P_{\text {crit }}\left(3.47,95 \%\right.$ CI $\left.-5.11-12.05 \mathrm{cmH}_{2} \mathrm{O}\right)$ compared with nonsnorers $\left(0.49,95 \% \mathrm{CI}-7.7-8.68 \mathrm{cmH}_{2} \mathrm{O}\right.$; $\mathrm{p}<0.0001)$. This difference also persisted after adjusting for BMI, neck circumference, sex and age $(\mathrm{p}<0.025)$, indicating that other variables participate in the higher collapsibility of the pharynx in snorers.

\section{Sex}

Table 3 presents a comparison between males and females. Males and females were of similar BMI, but the females were older and had a smaller neck circumference. The $P_{\text {crit }}$ and OSA-RS of the females were similar to those of the males and remained similar after adjusting for differences in age, weight and neck circumference.

\section{Anthropometric parameters}

In the study subjects, $P$ crit correlated best with age $(\mathrm{R}=0.36$, $\mathrm{p}<0.0001)$, but the correlation with BMI $(\mathrm{R}=0.18)$ was also highly significant $(\mathrm{p}<0.006)$. As seen in figure 2 , subjects with high $P$ crit tended to be older and snorers. The effect of age on $P$ crit was similar in snorers and nonsnorers, in the mean number of subjects, every $10 \mathrm{yrs}$ was associated with an increase in $P$ crit of 0.66 and $0.68 \mathrm{cmH}_{2} \mathrm{O}$, respectively. Only one out of the 13 older obese subjects (aged $>60$ yrs with BMI $\geqslant 30 \mathrm{~kg} \cdot \mathrm{m}^{-2}$ ) had $P_{\text {crit }}<0$ (mean age, BMI and $P_{\text {crit for this group }}$ were $72.1 \pm 7.8 \mathrm{yrs}, \quad 32.7 \pm 2.4 \mathrm{~kg} \cdot \mathrm{m}^{-2}$ and $5.7 \pm 5.8 \mathrm{cmH}_{2} \mathrm{O}$, respectively), as compared with six out of the nine subjects aged $<30 \mathrm{yrs}$ with a BMI of $\leqslant 20 \mathrm{~kg} \cdot \mathrm{m}^{-2}(22.3 \pm 4.3 \mathrm{yrs}$, $19.0 \pm 1.1 \mathrm{~kg} \cdot \mathrm{m}^{-2}$ and $-1.9 \pm 2.4 \mathrm{cmH}_{2} \mathrm{O}$, respectively; $\mathrm{p}<0.002$ for $P_{\text {crit }}$ comparison of the two groups). The relatively low correlation between pharyngeal collapsibility and BMI was due, in part, to the difference between males and females (table 4). While the correlation between $P_{\text {crit }}$ and age was similar in both sexes, a significant correlation between $P_{\text {crit }}$ and BMI and neck circumference was only found in males. In a model that adjusts stepwise for these parameters, Pcrit correlated significantly in males only with age and neck circumference, both together producing a correlation of $\mathrm{R}=0.421$. In females, a significant adjusted correlation was found with age only $(R=0.40)$.

\section{OSA risk}

Figure 3 depicts the relationship between $P_{\text {crit }}$ and the OSARS. Increasing $P$ crit was associated with increased OSA-RS. The mean $P$ crit of 71 subjects at high risk for OSA (OSA-RS $\geqslant 2$ ) was $4.0(95 \% \mathrm{CI}-4.82-12.82) \mathrm{cmH}_{2} \mathrm{O}$, as compared with $0.69(95 \%$ CI -7.39-8.77) $\mathrm{cmH}_{2} \mathrm{O}$ for subjects with an OSA-RS $<2$ $(\mathrm{p}<0.001)$. However, the correlation between $P_{\text {crit }}$ and OSARS for all subjects was rather modest $(R=0.35)$, similar for both sexes (table 4 ), indicating that only slightly more than $12 \%$ of the individual variance in OSA-RS was explained by the passive hypotonic pharyngeal collapsibility.

\section{DISCUSSION}

The results of the present study confirm the hypothesis that the normal fully relaxed human $P_{\text {crit }}$ is close to or even above atmospheric, indicating that the anatomic properties of most healthy humans promote pharyngeal occlusion during profound relaxation, and muscle tone is mandatory in most people to maintain pharyngeal patency during sleep. In addition, it was found that age, weight and neck circumference accounted for a relatively small percentage of the variability in the relaxed $P_{\text {crit, }}$ and $P_{\text {crit }}$ explained only a small percentage of the individual variability in OSA-RS.

\section{Passive pharyngeal collapsibility}

The fact that the pharynx is occluded in most people under conditions of profound hypotony, such as anaesthesia or deep coma, is common knowledge and based on previous studies. SAFAR et al. [9] found complete or partial pharyngeal occlusion in $90 \%$ of their anaesthetised subjects. In post mortem studies of children, REED et al. [11] found a mean (range) closing pressure of $\sim 0(-2-5) \mathrm{cmH}_{2} \mathrm{O}$. Closure of the upper airway was reported to occur in most thin, normal adults during rapid eye movement (REM) sleep [12], as well as during central apnoeas in non-REM sleep [13]. EASTWOOD et al. [14] reported that $P_{\text {crit }}$ of healthy subjects rises with increasing concentrations of 


\begin{tabular}{|c|c|c|c|}
\hline & Propofol & Penthothal & All \\
\hline Subjects $\mathbf{n}$ & 192 & 35 & 227 \\
\hline Male \% & 51 & 60 & 52 \\
\hline Age yrs & $45.6 \pm 17.1$ & $45.6 \pm 17.1$ & $45.2 \pm 17.1$ \\
\hline BMI $\mathbf{k g} \cdot \mathrm{m}^{-2}$ & $26.2 \pm 4.4$ & $27.4 \pm 4.7$ & $26.5 \pm 4.5$ \\
\hline Neck circ. cm & $39.7 \pm 4.6$ & $41.2 \pm 3.6$ & $40.0 \pm 4.5$ \\
\hline OSA-RS 0-3 & $0.92 \pm 0.95$ & $1.14 \pm 1.19$ & $0.96 \pm 0.99$ \\
\hline Snoring \% & 42 & 46 & 43 \\
\hline Pcrit $\mathrm{cmH}_{2} \mathrm{O}$ & $1.60 \pm 4.36$ & $2.81 \pm 5.29$ & $1.78 \pm 4.51$ \\
\hline Rus $\mathrm{cmH}_{2} \mathrm{O}^{-1} \cdot \mathrm{L} \cdot \mathrm{s}^{-1}$ & $23.3 \pm 15.5$ & $25.9 \pm 15.0$ & $23.7 \pm 15.0$ \\
\hline
\end{tabular}

Data are presented as mean $\pm \mathrm{SD}$, unless otherwise stated. BMI: body mass index; circ: circumference; OSA-RS: obstructive sleep apnoea risk score (Berlin questionnaire); Pcrit: critical value of positive end-expiratory pressure; Rus: upstream resistance. None of the differences between groups was significant.

propofol anaesthesia, starting at mean of -0.3 and reaching $1.4 \mathrm{cmH}_{2} \mathrm{O}$. Propofol does not affect muscle tension directly [15], and the same finding was also reported with isuflorane anaesthesia [16], indicating that, as in the present study, the positive $P$ crit is not related to a specific anaesthetic. All these findings indicate that the negative values of hypotonic $P_{\text {crit }}$ obtained during sleep in healthy subjects are likely to represent, in addition to anatomic properties, substantial maintained muscle tone. The negative $P$ crit value measured in almost all anaesthetised, paralysed, healthy subjects by IsONO et al. [6] is probably due to the specific methodology that had to be used to assess the pharyngeal closing pressure during paralysis. In contrast, SAFAR [17] reported that ventilation of anaesthetised, curarised subjects through a face mask failed due to pharyngeal obstruction. It should be noted that, based on the mean slope of the hypotonic pharyngeal pressure-flow relationship observed during sleep [3, 4, 18],

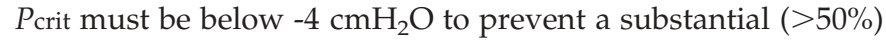
decrease in flow (hypopnoea) at atmospheric pressure.

\section{Comparison to collapsibility during sleep}

Earlier studies that evaluated Pcrit during sleep in health and disease did not use the methodology of hypotonic Pcrit measurement $[19,20]$. However, the presence of genioglossus electromyogram activity, both tonic and phasic, has also been documented during measurements of hypotonic Pcrit during sleep [3]. Similarly, $P_{\text {crit }}$ measured during the expiratory period in sleeping tracheotomised OSA patients was a mean $5 \mathrm{cmH}_{2} \mathrm{O}$ higher than during inspiration, indicating the presence of substantial neuromuscular activity that modulates collapsibility during sleep [21]. Interestingly, this value compares closely to the difference $\left(4.9 \mathrm{cmH}_{2} \mathrm{O}\right)$ between the $P_{\text {crit }}$ reported in healthy subjects during sleep [5] and that of the current nonsnoring subjects during anaesthesia. Accordingly, a positive (above atmospheric) $P_{\text {crit }}$ measured during sleep could be due to either disadvantageous anatomical properties or decreased residual neuromuscular tone maintained during sleep (fig. 4) or both. However, PATIL et al. [5] found a difference of $4.45 \mathrm{~cm} \mathrm{H}_{2} \mathrm{O}$ between the $P_{\text {crit }}$ of healthy subjects and that of patients with OSA during sleep, a

\begin{tabular}{|c|c|c|}
\hline \multirow[t]{2}{*}{ TABLE 2} & \multicolumn{2}{|c|}{$\begin{array}{l}\text { Comparison of nonsnorers and snorers } \\
\text { according to the Berlin questionnaire }\end{array}$} \\
\hline & Nonsnorers $^{\#}$ & Snorers \\
\hline Subjects $\mathrm{n}$ & 129 & 98 \\
\hline Male \% & 48 & 58 \\
\hline Age yrs & $38.5 \pm 15.6$ & $53.6 \pm 15.3^{\star \star \star}$ \\
\hline $\mathrm{BMI} \mathbf{k g} \cdot \mathrm{m}^{-2}$ & $25.0 \pm 4.2$ & $28.3 \pm 4.0^{\star \star \star}$ \\
\hline Neck circ. cm & $38.4 \pm 4.1$ & $42.0 \pm 4.3^{* * *}$ \\
\hline OSA-RS ${ }^{\circ} 0-3$ & $0.38 \pm 0.59$ & $1.76 \pm 0.87^{\star \star \star}$ \\
\hline$P_{\text {crit' }} \mathrm{cmH}_{2} \mathrm{O}$ & $0.39 \pm 4.01$ & $3.40 \pm 4.27^{\star \star \star}$ \\
\hline Rus $\mathrm{cmH}_{2} \mathrm{O}^{-1} \cdot \mathrm{L} \cdot \mathrm{s}^{-}$ & $23.2 \pm 11.8$ & $24.5 \pm 18.5$ \\
\hline
\end{tabular}

Data are presented as mean $\pm \mathrm{SD}$, unless otherwise stated. BMI: body mass index; circ: circumference; OSA-RS: obstructive sleep apnoea risk score; $P$ crit: critical value of positive end-expiratory pressure; Rus: upstream resistance. \#: nonsnorers were significantly younger, leaner, had a smaller neck circumference and higher OSA-RS and $P_{\text {crit; }}{ }^{\prime}$ : difference between $P_{\text {crit }}$ and OSA-RS between nonsnorers and snorers remained highly significant after adjusting for the anthropometric differences. ${ }^{* *}: p<0.001$, for comparison between nonsnorers and snorers.

magnitude almost identical to the difference in $P_{\text {crit }}$ found in the present study between subjects with an OSA-RS of 0 and 3 $\left(4.35 \mathrm{cmH}_{2} \mathrm{O}\right)$. This comparison suggests that the mean magnitude of the neuromuscular tone included in and affecting collapsibility during sleep is similar in healthy subjects and OSA patients (fig. 3), and therefore that the increased collapsibility of the pharynx of OSA subjects during sleep is due primarily to anatomic factors (fig. 3). This conclusion is also supported by the finding that anaesthetised patients who needed positive pressure to maintain airway patency had more severe sleep-disordered breathing (particularly during REM sleep) than those whose airways remained

$\begin{array}{ll}\text { TABLE } 3 & \begin{array}{l}\text { Study characteristics according to sex of } \\ \text { subjects }\end{array}\end{array}$

\begin{tabular}{|c|c|c|}
\hline & Male & Female $^{\#}$ \\
\hline Subjects $\mathrm{n}$ & 119 & 108 \\
\hline Age yrs & $42.7 \pm 16.5$ & $47.9 \pm 17.2^{*}$ \\
\hline BMI $\mathbf{k g} \cdot \mathrm{m}^{-2}$ & $26.3 \pm 4.0$ & $26.7 \pm 5.0$ \\
\hline Neck circ. cm & $42.0 \pm 3.9$ & $37.8 \pm 3.9^{* * *}$ \\
\hline OSA-RS ${ }^{\oplus} 0-3$ & $0.94 \pm 1.07$ & $0.98 \pm 0.91$ \\
\hline Snoring \% & 48 & 39 \\
\hline$P_{\text {crit }}^{\top} \mathrm{cmH}_{2} \mathrm{O}$ & $2.05 \pm 5.01$ & $1.43 \pm 3.94$ \\
\hline Rus $\mathrm{cmH}_{2} \mathrm{O}^{-1} \cdot \mathrm{L} \cdot \mathrm{s}^{-1}$ & $24.9 \pm 18.3$ & $22.6 \pm 10.2$ \\
\hline
\end{tabular}

Data are presented as mean $\pm \mathrm{SD}$, unless otherwise stated. BMI: body mass index; circ.: circumference; OSA-RS: obstructive sleep apnoea risk score; Pcrit: critical value of positive end-expiratory pressure; Rus: upstream resistance. \# . older than males, with smaller neck circumference; ${ }^{\prime}$ : differences between males and females (both unadjusted and adjusted for the difference in age and neck size) were not significant. *: $p<0.05$, for comparison between male and female subjects; ${ }^{\star \star *}: p<0.001$, for comparison between male and female subjects. 


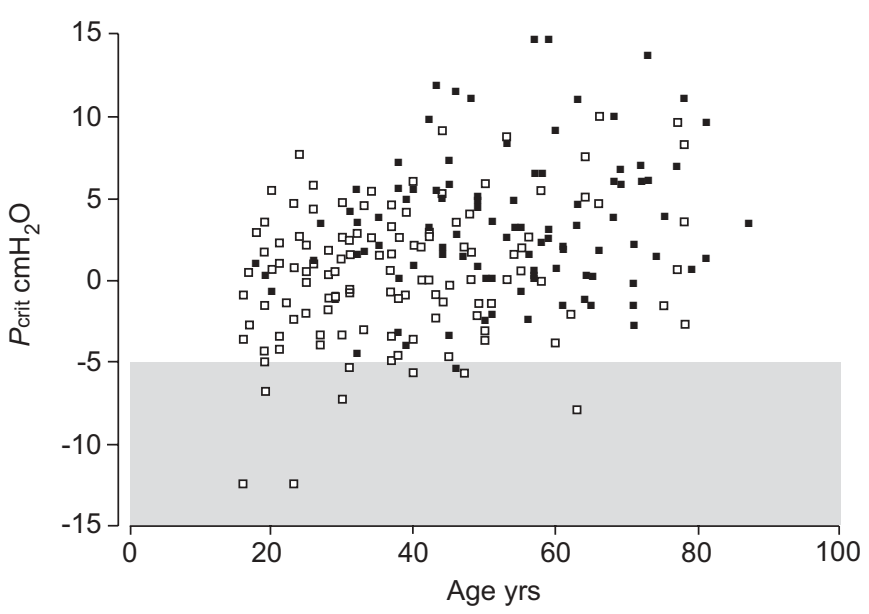

FIGURE 2. Relationship between critical value of positive-end expiratory pressure ( $P_{\text {crit }}$ and age in 227 subjects. $\square$ : nonsnorers; $\square$ : snorers. $\square$ : "safe" $P$ crit that prevents hypopnoeas.

patent at or below atmospheric pressure [22]. Obviously, these mean data do not contradict the possibility that individual subjects with high passive pharyngeal collapsibility may maintain active neuromuscular compensation that prevents obstruction [5]. The finding that the relaxed Pcrit of most humans is positive explains why most healthy subjects develop occasional apnoeas and or hypopnoeas (per definition $\geqslant 5 \cdot h^{-1}$ ), as well as snoring or plain OSA when normal dilator drive is reduced by drugs or alcohol.

\section{Effects of anaesthesia}

The relevance of findings observed under anaesthesia compared with sleep and OSA has been previously documented [22]. Propofol anaesthesia is even sometimes referred to as "drug-induced sleep" [23]. In order to recruit a large cohort of subjects from the community, the present authors had to abbreviate the study protocol to a minimum. Therefore, no attempt was made to establish a prolonged steady state of anaesthesia during the pressure-flow measurements, or to measure or reach a pre-defined level of anaesthesia. The

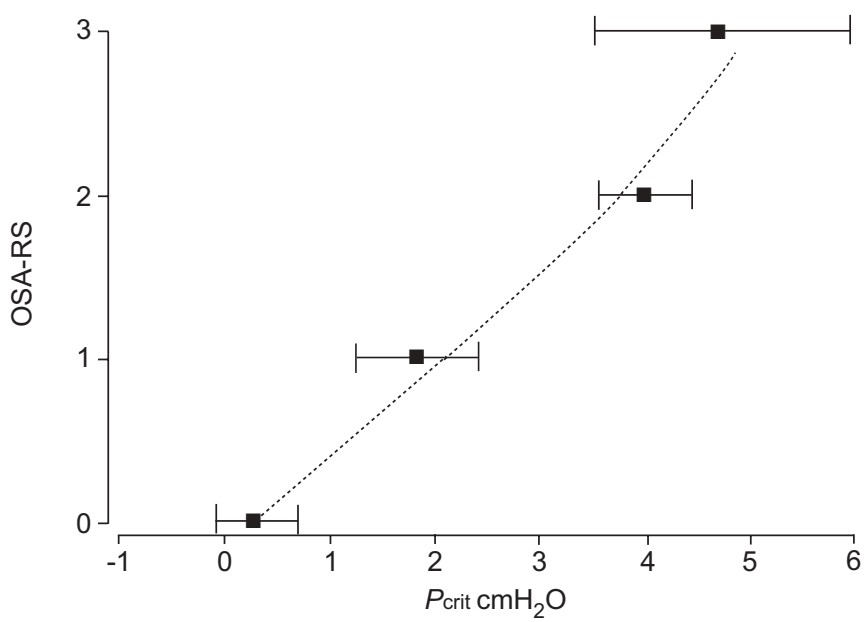

FIGURE 3. Relationship between critical value of positive end-expiratory pressure $\left(P_{\text {crit }}\right)$ and the obstructive sleep apnoea risk score (OSA-RS). P $P_{\text {crit }}$ is presented as mean \pm SEM for each level of OSA-RS

potential effect of possible minor anaesthesia dissipation during the few minutes required to assess $P_{\text {crit }}$ was neutralised by randomising the order of pressure drops performed to measure pressure-flow relationships. In addition, the anaesthesiologists used the same protocol to administer the anaesthetics, and the same clinical criteria to ascertain adequate and stable anaesthesia in all subjects. With the relatively large number of subjects studied, the present authors believe that differences in mean $P_{\text {crit }}$ between groups are unlikely to be due to differences in response to propofol. However, the lack of objective measurements of the depth of anaesthesia, both in the current study and previous studies that measured Pcrit under anaesthesia, limits comparison of results between studies. However, the lack of a more standardised mode of anaesthesia does not affect the main finding of the present study, namely that $P_{\text {crit }}$ is above atmospheric in most healthy subjects while anaesthetised. In actual fact, deeper anaesthesia would be expected to increase the mean $P_{\text {crit }}$ and the number of subjects with positive $P_{\text {crit }}$ $[14,16]$, and it is possible that in some subjects, a negative $P_{\text {crit }}$ was found due to more superficial anaesthesia.

\section{TABLE 4 Unadjusted Pearson's correlation}

\begin{tabular}{|c|c|c|c|c|}
\hline & Age yrs & $\mathrm{BMI} \mathbf{k g} \cdot \mathrm{m}^{-2}$ & Neck circ. cm & OSA-RS 0-3 \\
\hline \multicolumn{5}{|l|}{ Males ${ }^{\#}$} \\
\hline $\mathrm{BMI} \mathrm{kg} \cdot \mathrm{m}^{-2}$ & $0.34^{\S}$ & & & \\
\hline OSA-RS 0-3 & $0.55^{\S}$ & $0.54^{\S}$ & $0.53^{\S}$ & \\
\hline$P$ crit $\mathrm{CmH}_{2} \mathrm{O}$ & $0.37^{\S}$ & $0.27^{\star \star *}$ & $0.31^{\S}$ & $0.34^{\S}$ \\
\hline \multicolumn{5}{|l|}{ Females } \\
\hline OSA-RS 0-3 & $0.57^{\S}$ & $0.47^{\S}$ & $0.28^{+}$ & \\
\hline Pcrit $\mathrm{cmH}_{2} \mathrm{O}$ & $0.40^{\S}$ & 0.10 & 0.09 & $0.37^{\S}$ \\
\hline
\end{tabular}

BMI: body mass index; circ.: circumference; OSA-RS: obstructive sleep apnoea risk score; Pcrit: critical value of positive end-expiratory pressure. ${ }^{\#}: \mathrm{n}=119 ;{ }^{\circ}: \mathrm{n}=108$ : $+: p<0.002{ }^{* * *}: p<0.001 ;{ }^{s}: p<0.0001$. 


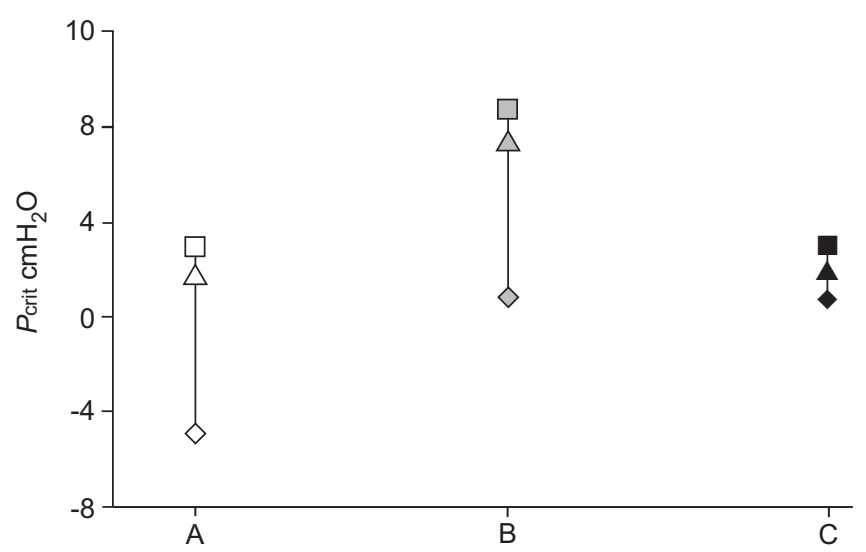

FIGURE 4. Schematic representation of possible relationships between anatomic, completely relaxed positive end-expiratory pressure ( $\left.P_{\text {crit; }} \square, \mathbf{\square}, \mathbf{\square}\right)$, $P$ crit under anaesthesia (assumed to be very close to the anatomic Pcrit; $\Delta, \boldsymbol{\Delta}, \boldsymbol{\Delta}$ ) and hypotonic $P$ crit observed in previous studies during sleep $(\diamond, \diamond, \diamond)$. A: healthy population with positive anatomic $P$ crit who retained neuromuscular tone maintaining a negative hypotonic $P$ crit during sleep. B: population with increased anatomic collapsibility. Despite neuromuscular tone equal to healthy subjects, $P$ crit will be positive during sleep, promoting obstructive sleep apnoea. C: patients with normal anatomy but due to reduced neuromuscular tone during sleep; the resultant

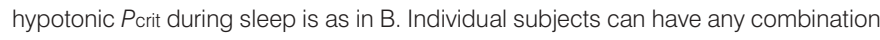
of the above, as well as increased neuromuscular tone during sleep, which may compensate for unfavourable anatomy.

\section{OSA-RS}

A well-standardised and validated OSA risk scoring system was used to estimate the prevalence of OSA in the study subjects [10, 24]. Although polysomnography would have provided a more accurate estimate of the individual apnoea/hypopnoea index (AHI), the Berlin questionnaire is a well-accepted tool to estimate the prevalence of OSA, which is validated in primary care settings. This instrument is used to classify subjects who are at high and low risk for OSA by identifying snoring behaviour, daytime sleepiness, obesity and hypertension, and has a positive predictive value of 0.89 . In the validation study, $744(37.5 \%)$ primary care patients were identified as being at high risk for OSA (29-44\% in different clinics) [24]. In later studies of 8,000 (32\%) primary care patients [24] and 1,506 (26\%) adults from the general population [25] a high probability for OSA was noted, based on the Berlin questionnaire. As the current study subjects arrived at the hospital for simple elective surgery unrelated to OSA or OSA risk factors, they could be considered, for the study purpose, as a random population similar to primary care patients. The prevalence of high risk OSA in the present study $(31.3 \%)$ was within this range. In the Berlin questionnaire validation study, NETZER et al. [10] reported a mean AHI of 21.1 and 4.7 in the high- and low-risk groups, respectively. Despite the low prevalence of OSA expected in the low-risk group in the present study, not only did the majority of the subjects have a positive Pcrit but, even when considering the subset of nonsnorers with low OSA-RS, 57 and $95 \%$ of subjects had a $P_{\text {crit }}>0$ and $>-5$, respectively.

\section{Anthropometric parameters and Pcrit}

Although the present study did not measure the true anatomic $P_{\text {crit, }}$ the difference between anaesthesia-induced hypotony and complete muscle relaxation was probably small, as only a minor increase in $P$ crit was found in anaesthetised dogs after dissection of the hypoglossus nerves [26]. Therefore, the Pcrit measured during anaesthesia is likely to enable an accurate assessment of the relationship between anatomic collapsibility and anthropometric parameters. In addition, as opposed to previous studies that compared similar parameters to measures of collapsibility in OSA patients [7, 20], the present authors could assess this relationship in a mixed general population, the majority of whom had no OSA. It was found that pharyngeal collapsibility explained only $12.25 \%$ of the variance of individual OSA-RS in the general population, a substantially lower estimate than that reported for the severity of OSA in OSA patients [7]. The prevalence of OSA is known to increase with age $[7,25,27-30]$. In the present study, the highest correlation was found between Pcrit and age, which was similar in males and females, confirming previous studies $[7,30]$. However, the correlation between OSA-RS and age remained significant after adjusting for $P_{\text {crit, indicating that }}$ increased prevalence of OSA with age is not only due to anatomic collapsibility. OSA is also more common in males $[20,25,28,29,31]$. Nevertheless, a sex difference in Pcrit was not found after adjusting for age and BMI, similar to previous studies that assessed collapsibility during sleep [7, 32] and the study by YOUNES [7], which related the higher prevalence of OSA in males to their higher flow demand. In addition, the association between BMI and the prevalence of OSA is well documented [7, 25, 28, 29], and an association between pharyngeal collapsibility and BMI was reported in OSA patients (almost all male), both during sleep [7, 33] and paralysis [34]. However, this correlation, as well as the correlation between $P_{\text {crit }}$ and neck circumference, was only statistically significant in the present study for males, confirming previous assumptions that differences in weight distribution between males and females affect pharyngeal collapsibility more than being overweight. When a stepwise regression analysis was performed for variables that correlate with collapsibility, with $P_{\text {crit }}$ as the dependent variable and age, BMI and neck circumference as independent variables, the variables included in the model accounted for only $16.8 \%$ of the variability in $P$ crit. This finding suggests that in the general population, other factors play a more important role in determining collapsibility, probably individual cephalometric characteristics, independently of age and weight.

In conclusion, the current findings indicate the following. 1) The human pharynx is almost always fully or substantially occluded in the absence of neuromuscular support. 2) The anatomic collapsibility is higher in snorers and in patients with high obstructive sleep apnoea risk score. 3) Anatomy seems to explain only a small part of the variance in obstructive sleep apnoea prevalence in the general population. 4) Hypotonic critical value of positive end-expiratory pressure of the general population is similar in males and females after adjusting for confounders. It rises with increasing age but is only affected by neck circumference in males. 5) Factors other than age, weight and neck circumference determine most of the variance of pharyngeal collapsibility. 6) Comparing the critical value of positive-end expiratory pressure found in the present study with that reported during sleep suggests that substantial residual neuromuscular tone is maintained during sleep in both healthy subjects and obstructive sleep apnoea patients. 


\section{REFERENCES}

1 Schwartz AR, Smith PL, Wise RA, Permutt S. Effect of nasal pressure on upper airway pressure flow relationships. J Appl Physiol 1989; 66: 1626-1634.

2 Smith PL, Wise RA, Gold AR, Schwartz AR, Permutt S. Upper airway pressure-flow relationships in obstructive sleep apnea. J Appl Physiol 1988; 64: 789-795.

3 Schwartz AR, O'Donnell CP, Baron J, et al. The hypotonic upper airway in obstructive sleep apnea. Role of structures and neuromuscular activity. Am J Respir Crit Care Med 1998; 157: 1051-1057.

4 Patil SP, Schneider H, Schwartz AR, Smith PL. Adult obstructive sleep apnea: pathophysiology and diagnosis. Chest 2007; 132: 325-337.

5 Patil SP, Schneider H, Marx JJ, Gladmon E, Schwartz AR, Smith PL. Neuromechanical control of upper airway patency during sleep. J Appl Physiol 2007; 102: 547-556.

6 Isono S, Remmers JE, Tanaka A, Sho Y, Sato J, Nishino T. Anatomy of pharynx in patients with obstructive sleep apnea and in normal subjects. J Appl Physiol 1997; 82: 1319-1326.

7 Younes M. Contributions of upper airway mechanics and control mechanisms to severity of obstructive apnea. Am J Respir Crit Care Med 2003; 168: 645-658.

8 Pierce R, White DP, Malhotra A, et al. Upper airway collapsibility, dilator muscle activation and resistance in sleep apnoea. Eur Respir J 2007; 30: 345-353.

9 Safar P, Escarraga LS, Chang F. Upper airway obstruction in the unconscious patient. J Appl Physiol 1959; 14: 760-764.

10 Netzer NC, Stoohs RA, Netzer CM, Clark K, Strohl KP. Using the Berlin questionnaire to identify patients at risk for the sleep apnea syndrome. Ann Int Med 1999; 131: 485-491.

11 Reed WR, Roberts JL, Thach BT. Factors influencing regional patency and configuration of the human infant upper airway. J Appl Physiol 1985; 58: 635-644.

12 Strohl KP, Cherniack NS, Gothe B. Physiologic basis of therapy for sleep apnea. Am Rev Respir Dis 1986; 134: 791-802.

13 Badr MS, Toiber F, Skatrud JB, Dempsey J. Pharyngeal narrowing/occlusion during central sleep apnea. J Appl Physiol 1995; 78: 1806-1815.

14 Eastwood PR, Platt PR, Shepherd K, Maddison K, Hillman DR. Collapsibility of the upper airway at different concentrations of propofol anesthesia. Anesthesiology 2005; 103: 470-477.

15 Ginz HF, Zorzato F, Iaizzo PA, Urwyler A. Effect of three anaesthetic techniques on isometric skeletal muscle strength. Br J Anaesth 2004; 92: 367-372.

16 Eastwood PR, Szollosi I, Platt PR, Hillman DR. Collapsibility of the upper airway during anesthesia with isoflurane. Anesthesiology 2002; 97: 786-793.

17 Safar P. Failure of manual respiration. J Appl Physiol 1959; 14: 84-88.

18 Oliven A, O'Hearn DJ, Boudewyns A, et al. Upper airway response to electrical stimulation of the genioglossus in obstructive sleep apnea. J Appl Physiol 2003; 95: 2023-2029.
19 Gleadhill IC, Schwartz AR, Schubert N, Wise RA, Permutt S, Smith PL. Upper airway collapsibility in snorers and in patients with obstructive sleep apnea. Am Rev Respir Dis 1991; 143: 1300-1303.

20 Sforza E, Petiau C, Weiss T, Thibault A, Krieger J. Pharyngeal critical pressure in patients with obstructive sleep apnea syndrome: clinical implications. Am J Respir Crit Care Med 1999; 159: 149-157.

21 Schneider H, Boudewyns A, Smith PL, et al. Modulation of upper airway collapsibility during sleep: influence of respiratory phase and flow regimen. J Appl Physiol 2002; 93: 1365-1376.

22 Eastwood PR, Szollosi I, Platt PR, Hillman DR. Comparison of upper airway collapse during general anaesthesia and sleep. Lancet 2002; 359: 1207-1209.

23 Boudewyns A, Marklund M, Hochbab W. Alternatives for OSAHS treatment: selection of patients for upper airway surgery and oral appliances. Eur Respir Rev 2007; 16: 132-145.

24 Netzer NC, Hoegel JJ, Loube D, et al. Sleep in primary care international study group: prevalence of symptoms and risk of sleep apnea in primary care. Chest 2003; 124: 1406-1414.

25 Hiestand DM, Britz P, Goldman M, Phillips B. Prevalence of symptoms and risk of sleep apnea in the US population: results from the national sleep foundation sleep in America 2005 poll. Chest 2006; 130: 780-786.

26 Oliven A, Odeh M, Schnall RP. Improved upper airway patency elicited by electrical stimulation of the hypoglossus nerves. Respiration 1996; 63: 213-216.

27 Bixler EO, Vgontzas AN, Ten Have T, Tyson K, Kales A. Effects of age on sleep apnea in men: I. Prevalence and severity. Am J Respir Crit Care Med 1998; 157: 144-148.

28 White DP. The pathogenesis of obstructive sleep apnea. Advances in the past 100 years. Am J Respir Cell Mol Biol 2006; 34: 1-6.

29 Young T, Shahar E, Nieto FJ, et al. Predictors of sleepdisordered breathing in community dwelling adults: the Sleep Heart Health Study. Arch Intern Med 2002; 162: 893-900.

30 Eikermann M, Jordan AS, Chamberlin NL, et al. The influence of aging on pharyngeal collapsibility during sleep. Chest 2007; 131: 1702-1709.

31 Malhotra A, Huang Y, Fogel RB, et al. The male predisposition to pharyngeal collapse: importance of airway length. Am J Respir Crit Care Med 2002; 166: 1388-1395.

32 Rowley JA, Zhou X, Vergine I, Shkoukani MA, Badr MS. Influence of gender on upper airway mechanics: upper airway resistance and Pcrit. J Appl Physiol 2001; 91: 2248-2254.

33 Schwartz AR, Gold AR, Schubert N, et al. Effect of weight loss on upper airway collapsibility in obstructive sleep apnea. Am Rev Respir Dis 1991; 144: 494-498.

34 Watanabe $\mathrm{T}$, Isono $\mathrm{S}$, Tanaka $\mathrm{A}$, Tanzawa $\mathrm{H}$, Nishino $\mathrm{T}$. Contribution of body habitus and craniofacial characteristics to segmental closing pressures of the passive pharynx in patients with sleep-disordered breathing. Am J Respir Crit Care Med 2002; 165: 260-265. 